\title{
Application of Grade Algorithm Based Approach along with PV Analysis for Enhancement of Power System Performance
}

\author{
G. Kannan', D. Padma Subramaniam², Solai Manokar ${ }^{3}$ \\ ${ }^{1}$ Department of Electrical and Electronics Engineering, Amet University, Chennai, India \\ ${ }^{2}$ Sri Muthukumaran Institute of Technology, Chennai, India \\ ${ }^{3}$ Department of Electrical and Electronics Engineering, Anand Institute of Higher Technology, Chennai, India \\ Email: ganapathykannan@yahoo.com, subramanianpads@gmail.com
}

Received 12 May 2016; accepted 20 May 2016; published 29 August 2016

Copyright (C) 2016 by authors and Scientific Research Publishing Inc.

This work is licensed under the Creative Commons Attribution International License (CC BY). http://creativecommons.org/licenses/by/4.0/

(c) (7) Open Access

\section{Abstract}

This paper presents an application of GRADE Algorithm based approach along with PV analysis to solve multi objective optimization problem of minimizing real power losses, improving the voltage profile and hence enhancing the performance of power system. GRADE Algorithm is a hybrid technique combining genetic and differential evolution algorithms. Control variables considered are Generator bus voltages, MVAR at capacitor banks, transformer tap settings and reactive power generation at generator buses. The optimal values of the control variables are obtained by solving the multi objective optimization problem using GRADE Algorithm programmed using M coding in MATLAB platform. With the optimal setting for the control variables, Newton Raphson based power flow is performed for two test systems, viz, IEEE 30 bus system and IEEE 57 bus system for three loading conditions. Minimization of Real power loss and improvement of voltage profile obtained are compared with the results obtained using firefly and particle swarm optimization (PSO) techniques. Improvement of Loadability margin is established through PV curve plotted using continuation power flow with the real power load at the most affected bus as the bifurcation parameter. The simulated output shows improved results when compared to that of firefly and PSO techniques, in term of convergence time, reduction of real power loss, improvement of voltage profile and enhancement of loadability margin.

\section{Keywords}

Multi Objective Optimization, GRADE Algorithm, Loadability Margin, PV Curve, Real Power Loss Minimization, Voltage Profile Improvement 


\section{Introduction}

In Power systems planning and operation, voltage stability poses a major concern. Voltage instability or voltage collapse may come as a consequence of inadequate reactive power support from generators and transactions in transmission lines. Hence, understanding the concept of voltage stability and designing the prevention methodologies to mitigate the voltage instability is of great value to the utilities. Real Power versus Voltage (PV) analysis is useful for conceptual analysis of voltage stability and can be useful in specifying the active power margin.

Optimization of reactive power is proved to improve the voltage stability limits and to minimize system active power losses. Generator bus voltages, Transformer tap positions, the MVAR at the capacitor Banks and reactive power generation at generator buses are considered as the control variables. Many conventional methods used in VAR optimization are based on linear programming, nonlinear programming and quadratic programming method. The optimization of reactive power support to mitigate voltage collapse problem in power market systems was described using a sequential quadratic programming method [1] in 2003 by X. Lin et al.

The major drawbacks of the Conventional methods were that they were time consuming and they were not capable to solve complex problem with discrete variables. To overcome the disadvantages experienced in conventional methods, nature-inspired metaheuristic algorithms such as Genetic algorithm, colonial search algorithms and swarm intelligence techniques were proposed.

Comprehensive learning particle swarm optimization for reactive power dispatch [2] [3] were reported in 2007 \& 2010. Modified Swarm optimization method with admissible step and with minimization of constraint violation were reported in the same literature. A new Hybrid evolutionary strategy for reactive power dispatch [4] for controlling the reactive power generation in dispatching centers was reported in 2003 by D. Bhagwan Das and C. Patvardhan. This new method for solving optimization problem based on evolutionary strategy to improve the convergence and to find the better solution. Optimal reactive power dispatch based on different optimization techniques [5]-[11] were reported in various literatures.

Genetic algorithm [12] [13], employed for reactive power optimization is based on the mechanics of natural genetics. P. Devaraj and J. Preetha Roselyn have employed Genetic algorithm for voltage stability enhancement based on minimization of maximum L-indices of load buses. For effective genetic processing, the crossover and mutation operators which can immediately trade with the floating point numbers and integers were used.

Colonial search algorithms such as Ant colony and Binary Ant colony based optimization were also reported in reactive power optimization [14] [15]. It was established that the ants take tour based on aromatic substance called pheromone laid by them. The amount of pheromone will be high if the artificial ants finish their tour with a wide track and vice versa. The pheromone of the routes progressively decreases by evaporation in order to avoid the artificial ants getting stuck in the local optimum solution.

Differential Evolution (DE) algorithm was reported in various literatures [16]-[20] for reactive power optimization. DE combines the simple arithmetical operators with operators like recombination, mutation and selection thus evolving from a random population to the final population. Quasi-opposition teaching-learning based optimization (QOBL) [21] was employed for reactive power dispatch in IEEE 30 bus arrangement and was reported by Barun Mandal and Provas Kumar Roy. It was based on two basic operations, namely teaching (for global search) and learning (for local search) stage.

Comparative Study of Firefly algorithm and Particle Swarm Optimization for Noisy Non-Linear Optimization Problems was reported in 2012 by Saibal K. Pal et al. [22]. There are various noisy non-linear mathematical optimization problems that can be effectively solved by Metaheuristic Algorithms. These are iterative search processes that efficiently perform the exploration and exploitation in the solution space, efficiently find near optimal solutions. Firefly Algorithm is one of the recent evolutionary computing models which is inspired by fireflies behavior in nature. PSO is population based optimization technique inspired by social behavior of bird flocking or fish schooling. Preventive reactive power management for improving voltage stability margin [23]-[25] was reported by O. Alizadeh Mousavi et al. Adequate voltage stability margin needs to be obtained through the appropriate scheduling of the reactive power sources and also preventive counter measure to improve voltage stability margin through the management of the reactive power and its reserve.

In this paper, an algorithm namely GRADE algorithm is applied for solving multi objective optimization. The GRADE algorithm is based on a combination of genetic algorithm and differential evolution technique. The rest of this paper is organized as follows. In Section 2, a brief description of the formulation of the multi objective 
optimization problem along with equality and inequality constraints is presented. In Section 3, GRADE algorithm is presented in brief and the steps involved to solve multi objective optimisation problem is presented alongside a flowchart representing the same. In Section 4, the numerical results obtained during simulation for different loading conditions are explained in detail and analysis from the results is also presented. The conclusions are given in Section 5.

\section{Mathematical Problem Formulation}

The main objective of multi objective optimization is to minimize the active power loss in the transmission network, which is defined as follows:

$$
f_{1}=\min \sum_{n=1}^{n l} P_{\text {loss }}
$$

Another objective of this problem is to improve the voltage profile which is formulated mathematically as follows,

$$
f_{2}=\sum_{i=1}^{n}\left|V_{\text {max,spec }}-v\right|
$$

The overall objective function of the problem is thus formulated as follows,

$$
f=\alpha\left(f_{1}\right)+\beta\left(f_{2}\right)
$$

where, $P_{\text {loss }}=$ active power loss in the transmission network,

$V_{\text {max,spec }}=$ is the maximum voltage specified for all the buses,

$\alpha$ and $\beta$ are the penalty factors.

\section{Constraints}

Equality Constraints. The equality constraints include the real and reactive power constraints which are given as follows:

1) Real Power Constraint

$$
P_{i}(V, \theta)=\sum_{j=1}^{n} V_{i} V_{j}\left(G_{i j} \cos \theta_{i j}+B_{i j} \sin \theta_{i j}\right)
$$

where, $n=$ numbers of buses, except swing bus.

$G_{i j}=$ mutual conductance between bus $i$ and $j$.

$B_{i j}=$ mutual susceptance between bus $i$ and $j$.

$\theta_{i j}=$ Load angle between bus $i$ and $j$.

$P_{i}=$ Real power injected into network at bus $i$.

$V_{i}, V_{j}=$ Voltage magnitude at bus $i, j$.

2) Reactive Power Constraint

$$
Q_{i}(V, \theta)=\sum_{j=1}^{n} V_{i} V_{j}\left(G_{i j} \sin \theta_{i j}+B_{i j} \cos \theta_{i j}\right)
$$

where, $n=$ number of buses, except swing bus.

$Q_{i}=$ Reactive power injected into network at bus $i$.

Inequality Constraints. The inequality constraints include the following,

1) Bus Voltage Magnitude Constraint

$$
V_{i, \text { min }} \leq V_{i} \leq V_{i, \max } ; i \in N_{B} \text { : Total number of buses }
$$

where, $V_{i}=$ Voltage magnitude at bus $i$.

$N_{B}=$ Total number of buses.

2) Generator Bus Reactive Power Constraint

$$
Q_{G i, \min } \leq Q_{G i} \leq Q_{G i, \max }, i \in N_{g}
$$


where, $Q_{G i}=$ Reactive power generation at bus $i$.

$N_{g}=$ Number of generator buses.

3) Reactive Power Source Capacity Constraints

$$
Q_{C i \text {,min }} \leq Q_{C i} \leq Q_{C i, \max } ; i \in N_{C}
$$

where, $Q_{C i}=$ Reactive power generated by $\mathrm{i}^{\text {th }}$ capacitor bank.

$N_{C}=$ No. of capacitor banks.

4) Transformer Tap Position Constraints:

$$
T_{k, \text { min }} \leq T_{k} \leq T_{k, \text { max }} ; i \in N_{T}
$$

where, $T_{k}=$ Tap setting of transformer at branch $k$.

$N_{T}=$ No. of tap-setting transformer branches.

\section{GRADE Optimization Algorithm}

The GRADE algorithm is a combination of genetic algorithm and differential evolution technique. The algorithmic scheme of GRADE algorithm is really alike to that of the genetic algorithm except that it uses the simplified differential operator like the differential evolution technique. The parameters used in GRADE Algorithm are given in Table 1.

GRADE algorithm uses 3 genetic operators which include mutation, crossing and selection.

Mutation operator

Mutation operator is applied to the parental population, thus producing a new population of offsprings. From the unit interval, a random number $\mathrm{p}$ is generated for each parent $\mathrm{P}$. One offspring $\mathrm{O}$ is created by mutation for a parent $\mathrm{P}$ if $\mathrm{p}$ is smaller than radioactivity. In such a case, the new random point RP is generated inside a given domain and new offspring $\mathrm{O}$ is created on a random position on the line connecting the parent $\mathrm{P}$ and the random point RP. This operator creates each time different number of offsprings, but in average this number should converge to population_size * radioactivity. Radioactivity is a control parameter of GRADE algorithm defining the part of offsprings created by mutation.

Crossover Operator

Crossover operator is designated to create such a number of new offsprings, that the total number of offsprings n_Offsprings will be the same as parents n_Parents (population will be doubled). To create an offspring, two members P1 and P2 of parental population are randomly chosen. Then the vector of their difference is computed, multiplied by cross_rate and added to the better one between P1 and P2. Cross_rate is a number each time randomly generated from the interval (0; cross_limit). cross_limit is another control parameter of GRADE algorithm.

Selection Operator

Operator selection should select new population from parents and offsprings or more precisely, it eliminates chosen offsprings and parents, until the complete population has its initial size. Each time when one member is rejected, best members are selected for next generation and the worse of them is discarded. This selection process has two advantages: It ensures that the best member will survive to the next generation, even very bad member has a possibility to survive and certain diversity of population remains.

The GRADE algorithm suffers from serious disadvantage that it tends to form clusters. In order to overcome this disadvantage a niching strategy called CERAF strategy is employed. It produces areas of higher level of "radioactivity" in the neighborhood of all previously found local extremes by increasing the mutation probability (i.e. ceraf radioacitivity) in these areas many times. Parameters used to implement CERAF strategy and the corresponding values employed are given in Table 2.

Table 1. Parameters in GRADE algorithm.

\begin{tabular}{cc}
\hline Parameter & Description Used Value \\
\hline $\begin{array}{c}\text { pop_rate } \\
\text { Radioactivity } \\
\text { cross_limit }\end{array}$ & Control the size of population \\
\hline
\end{tabular}


Table 2. Parameters in CERAF strategy.

\begin{tabular}{cccc}
\hline Parameter & Description Used Value & & \\
\hline RAD & Control the radius of the radioactivity area & 0.25 & RAD \\
deact_rate & Control the decreasing in size of radioactive area & 0.995 & deact_rate \\
Quiet & Control number of generations before new local extreme is marked & 100 & Quiet \\
\hline
\end{tabular}

\section{Algorithm and Flowchart}

The GRADE algorithm used for searching an optimal solution for multi objective optimisation is given in Figure 1.

Step 1: Read the power flow data, set the minimum and maximum value of control variable and initiate transformer tap positions.

Step 2: Generate the initial population in random manner and assign the objective function value to all chromosomes in the population. The size of the population is then defined as the number of variables of objective function multiplied by parameter pop rate.

Step 3: Several new chromosomes are created using the mutation operators-the mutation and the local mutation (their total number depends on the value of a parameter called radioactivity—it gives the mutation probability).

Step 4: Create another set of new chromosomes using the simplified differential operator; thus doubling the population.

Step 5: Assign objective function values to all newly created chromosomes.

Step 6: Apply CERAF strategy.

Step 7: Apply selection operator to the double-sized population, thus decreasing the amount of individuals to its original value.

Step 8: Perform load flow analysis.

Step 9: Steps 3 - 7 are repeated until the variables are within their limits.

Step 10: Stopping criteria are checked, if satisfied the search process stops and displays the result, else proceed to the next iteration.

\section{Results and Discussion}

The effectiveness of GRADE algorithm based optimization technique is tested in IEEE 30-bus and 57-bus test systems and the results are compared with the results obtained using firefly and Particle Swarm Optimization algorithms. The proposed algorithm is developed in MATLAB 7 and run on a PC with INTEL i5 processor of 4GB RAM. For implementing GRADE technique, 30 trials each for different loading conditions are performed in the above mentioned test systems

\subsection{Results in IEEE-30 Bus System}

The standard IEEE 30-bus test system [10] is used to test the effectiveness of the proposed method. The test system consists of 6 generators, 4 transformers, and 41 branches. The transformers are at the branches 6 - 9, 6 10, 4 - 12 and 28 - 27. The reactive power support is provided at the buses 10 and 24.Line data and bus data of the test systems is available in [10] (Figure 2).

The reactive power generation limits for the IEEE 30-bus system are listed in Table 3 . The voltage and tap settings limit are provided in Table 4. The initial power loss for the IEEE 30-bus system is obtained as 0.17557 p.u by performing load flow analysis.

Different loading conditions are considered for multi objective optimization. The normal loaded condition has a load of 2.834 p.u and two other loading conditions of which one is light loaded and the other heavy loaded when compared to that of the normal loaded condition are considered.

In light loaded condition, the load is reduced by $50 \%$ of the normal load in all load buses and in heavy loaded condition, the load is increased by $50 \%$ of the normal load in all load buses. 


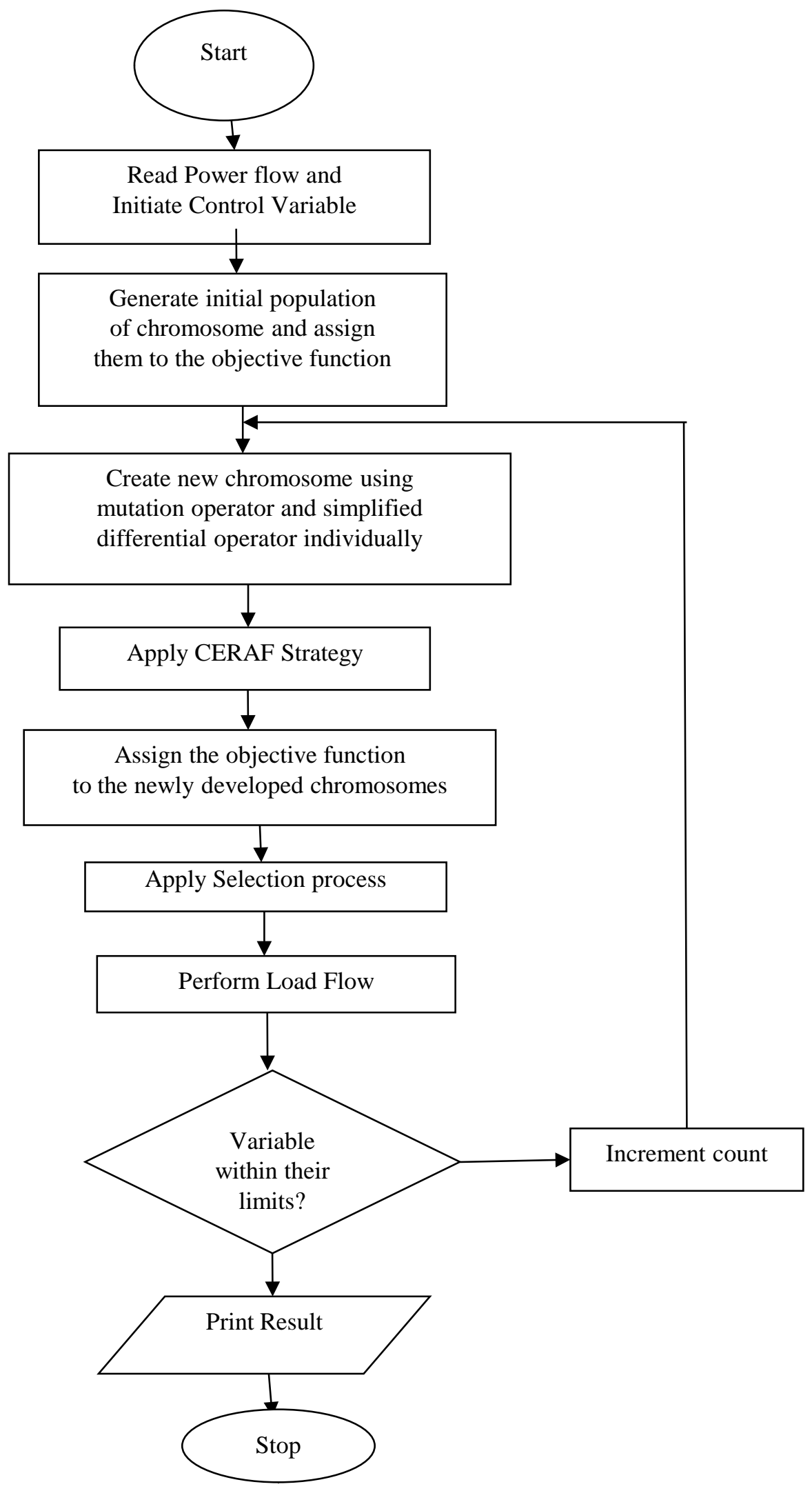

Figure 1. Flowchart of GRADE algorithm for multi objective optimisation. 


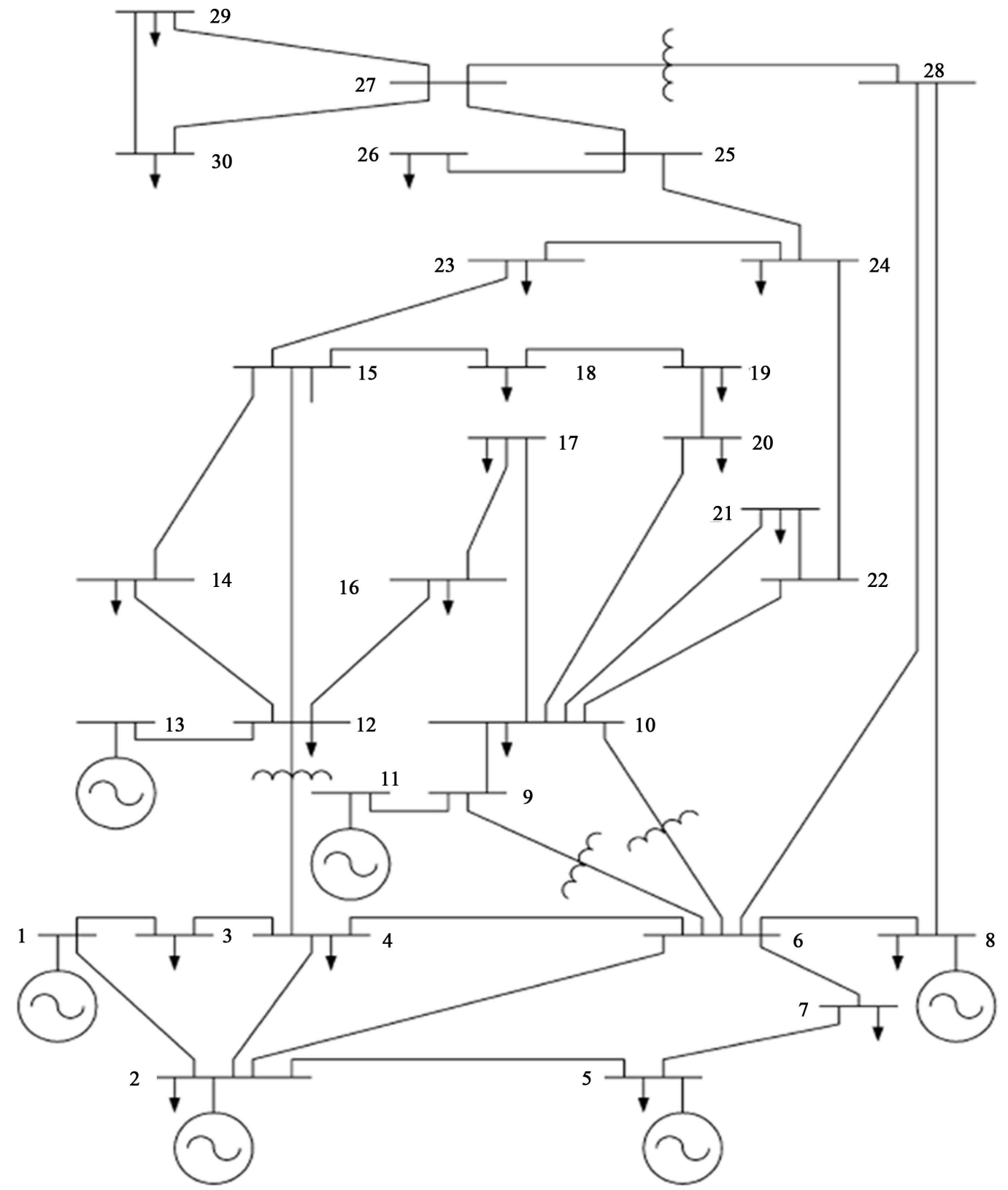

Figure 2. Single line diagram of IEEE 30 bus system.

Table 3. Limits for reactive power generation for IEEE30 bus system.

\begin{tabular}{ccccccc}
\hline Bus No & 1 & 2 & 5 & 8 & 11 & 13 \\
\hline$Q_{g \min }(M V A R)$ & 0 & -40 & -40 & -10 & -6 & -6 \\
$Q_{g \max }(M V A R)$ & 10 & 50 & 40 & 40 & 24 & 24 \\
\hline
\end{tabular}

Table 4. Limits for voltage and tap setting (in p.u.) for IEEE30 bus system.

\begin{tabular}{cccccc}
\hline$V_{G}^{\max }$ & $V_{G}^{\min }$ & $V_{\text {load }}^{\max }$ & $V_{\text {lood }}^{\min }$ & $T_{k}^{\max }$ & $T_{k}^{\min }$ \\
\hline 1.1 & 0.9 & 1.05 & 0.95 & 1.05 & 0.95 \\
\hline
\end{tabular}


Under light loaded condition the load is reduced to 1.4170 p.u and the base case loss is obtained as 0.037765 p.u. Under normal loaded condition the load is 2.834 p.u and the base case loss is obtained as 0.17557 p.u. Under heavily loaded condition the load is 4.2510 p.u and the base case loss is obtained as 0.4495 p.u. A comparison of fitness value for various loading condition is provided in Table 5 and a comparison of the real power loss obtained using PSO, Firefly and GRADE algorithm under three loading condition is shown in the Table 6.

From Table 6, it can be seen that, real power loss reduction is more when GRADE algorithm is used compared to conventional techniques such as firefly and particle swarm optimization technique.

After 30 trials the real power losses obtained by reactive power optimization using GRADE algorithm is presented in Table 6 along with worst and best results, mean and standard deviation in Table 7.

The optimal values of the control variables after optimization for three loading conditions are shown in Table 8.

Table 5. Comparison of fitness value for the three loading conditions.

\begin{tabular}{ccccccccccc}
\hline Parameter & \multicolumn{3}{c}{ Lightly loaded condition } & \multicolumn{3}{c}{ Normal loaded condition } & \multicolumn{3}{c}{ Heavily loaded condition } \\
\hline Optimization Technique & Firefly & PSO & GRADE & Firefly & PSO & GRADE & Firefly & PSO & GRADE \\
\hline Fitness Value & 0.12732 & 0.043762 & 0.043761 & 0.43534 & 0.20071 & 0.20069 & 1.4924 & 0.54832 & 0.54832 \\
\hline
\end{tabular}

Table 6. Comparison of real power loss for IEEE30 bus system.

\begin{tabular}{|ccccccccccc}
\hline Loading Condition & \multicolumn{4}{c}{ Lightly loaded condition } & \multicolumn{2}{c}{ Normal loaded condition } & \multicolumn{3}{c}{ Heavily loaded condition } \\
\hline Optimization Technique & Firefly & PSO & GRADE & Firefly & PSO & GRADE & Firefly & PSO & GRADE \\
\hline $\mathrm{P}_{\text {loss }}$ (p.u) & 0.035772 & 0.034768 & 0.034256 & 0.17476 & 0.16953 & 0.16939 & 0.43357 & 0.4339 & 0.4311 \\
\hline
\end{tabular}

Table 7. Comparison of best and worst case real power loss for IEEE30 bus system using Grade Algorithm.

\begin{tabular}{|c|c|c|c|c|c|c|c|c|c|c|c|c|}
\hline \multirow{2}{*}{$\begin{array}{c}\text { Loading Condition } \\
\text { Optimization } \\
\text { Technique }\end{array}$} & \multicolumn{4}{|c|}{ Lightly loaded condition } & \multicolumn{4}{|c|}{ Normal loaded condition } & \multicolumn{4}{|c|}{ Heavily loaded condition } \\
\hline & Worst & Best & Mean & $\begin{array}{c}\text { Std. } \\
\text { Deviation }\end{array}$ & Worst & Bect & Mean & $\begin{array}{c}\text { Std. } \\
\text { Deviation }\end{array}$ & Vorst & Best & Mean & $\begin{array}{c}\text { Std. } \\
\text { Deviation }\end{array}$ \\
\hline $\mathrm{P}_{\text {loss }}(\mathrm{p} . \mathrm{u})$ & 3.8002 & 3.4756 & 3.5657 & 0.10135 & 19.954 & 16.939 & 17.7497 & 0.672046 & 43.683 & 43.41 & 43.2472 & 0.3058 \\
\hline
\end{tabular}

Table 8. Optimal values of the control variables in p.u. obtained using grade algorithm for IEEE30 bus system.

\begin{tabular}{cccc}
\hline Control variables & Lightly loaded condition & Normal loaded condition & Heavily loaded condition \\
$\mathrm{V}_{1}$ & 1.1 & 1.1 & 1.1 \\
$\mathrm{~V}_{2}$ & 1.1 & 1.1 & 1.1 \\
$\mathrm{~V}_{5}$ & 1.1 & 1.1 & 1.0890 \\
$\mathrm{~V}_{8}$ & 1.1 & 1.1 & 1.1 \\
$\mathrm{~V}_{11}$ & 1.0999 & 1.1 & 1.1 \\
$\mathrm{~V}_{13}$ & 1.1 & 1.1 & 1.0767 \\
$\mathrm{Q}_{\mathrm{C} 10}$ & 0.27648 & 0.50 & 0.20 \\
$\mathrm{Q}_{\mathrm{C} 24}$ & 0.048992 & 0.213704 & 0.20 \\
$\mathrm{~T}_{1}$ & 1.0003 & 0.970824 & 1.0484 \\
$\mathrm{~T}_{2}$ & 1.05 & 1.0157 & 0.95 \\
$\mathrm{~T}_{3}$ & 0.95 & 0.95 & 0.95 \\
$\mathrm{~T}_{4}$ & 0.97338 & 0.95 & 0.9759 \\
$\mathrm{Q}_{1}$ & 0.2806 & 0.0499289 & 0.10 \\
$\mathrm{Q}_{2}$ & -0.36843 & 0.10 & -0.40 \\
$\mathrm{Q}_{5}$ & -0.39967 & -0.40 & -0.096311 \\
$\mathrm{Q}_{8}$ & 0.049558 & -0.007805 & -0.10 \\
$\mathrm{Q}_{11}$ & -0.027887 & 0.239964 & 0.24 \\
$\mathrm{Q}_{13}$ & -0.06 & 0.141589 & -0.06 \\
\hline
\end{tabular}


From Table 8, it can be observed that, all control variables are set as per the optimum values obtained using GRADE Algorithm and the values are within the given specified limits. A comparison of voltage levels before and after optimization for lightly loaded condition, normal loaded condition and heavy loaded condition is also presented in Figures 3-5 respectively. The $30^{\text {th }}$ bus of the IEEE 30 bus system is found to be the weakest bus from power flow results and hence voltage at $30^{\text {th }}$ bus is compared to establish the effectiveness of GRADE Algorithm is improving the voltage profile.

It is noted that, from Figures 3-5 in all the loading conditions voltage profile improvement is optimum when controllers are tuned using GRADE Algorithm.

The result of continuation power flow analysis before and after optimization for different loading conditions

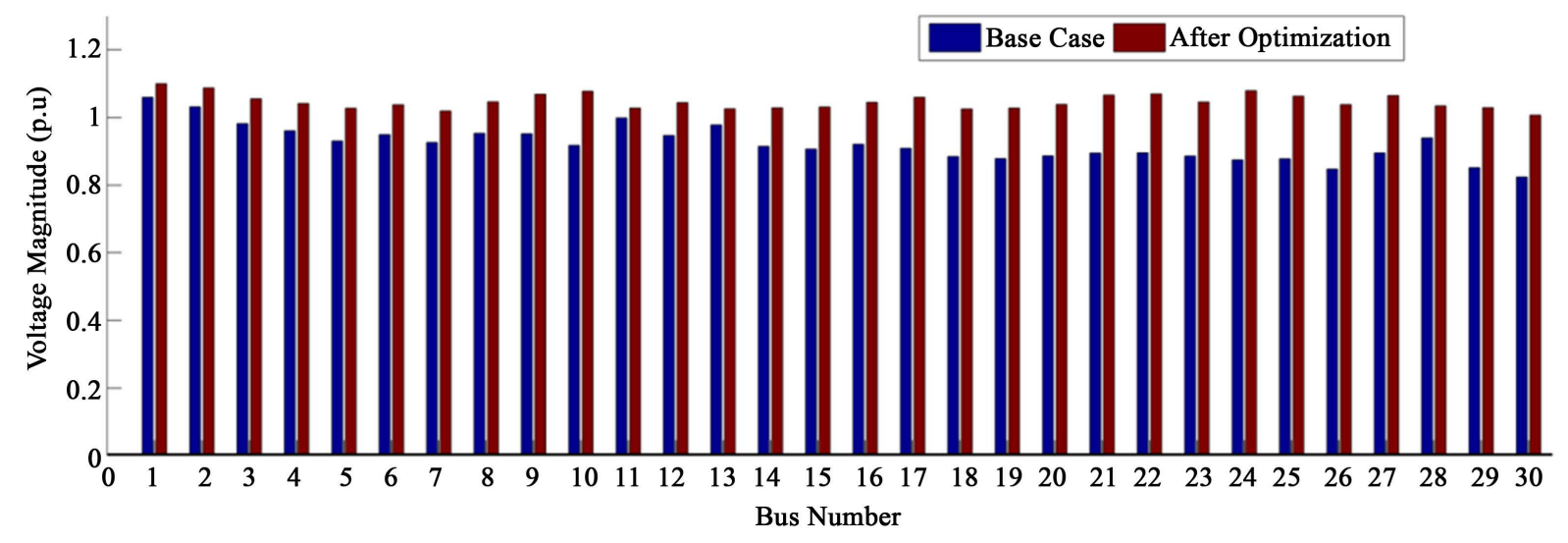

Figure 3. Comparison of voltage levels before and after optimization under light loaded condition for IEEE30 bus test system.

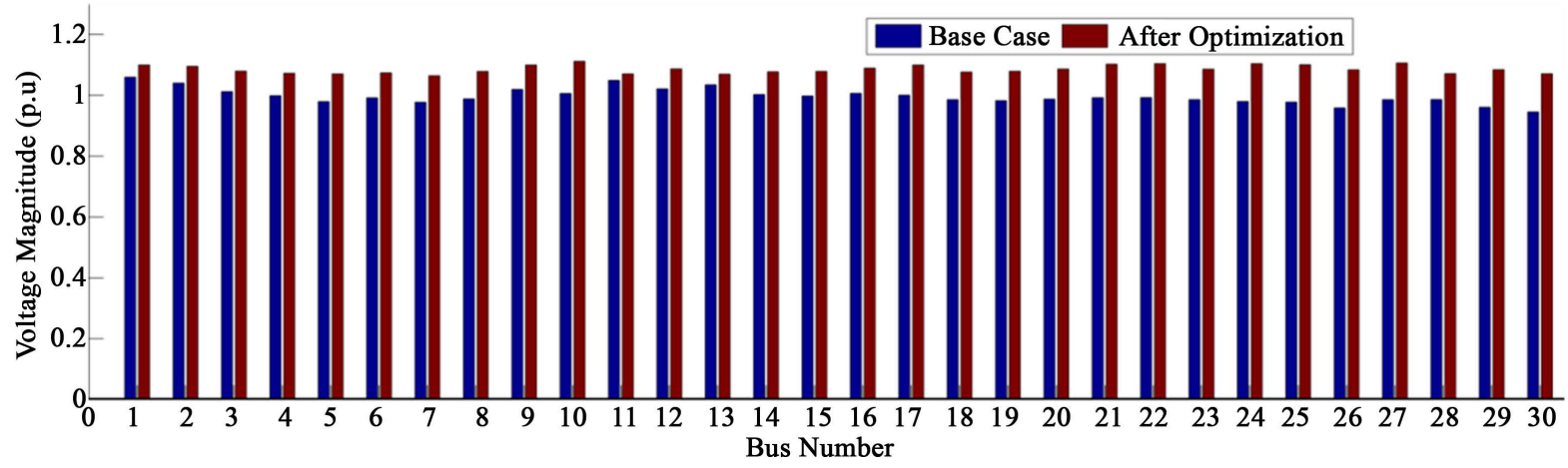

Figure 4. Comparison of voltage levels before and after optimization under normal loaded condition for IEEE30 bus test system.

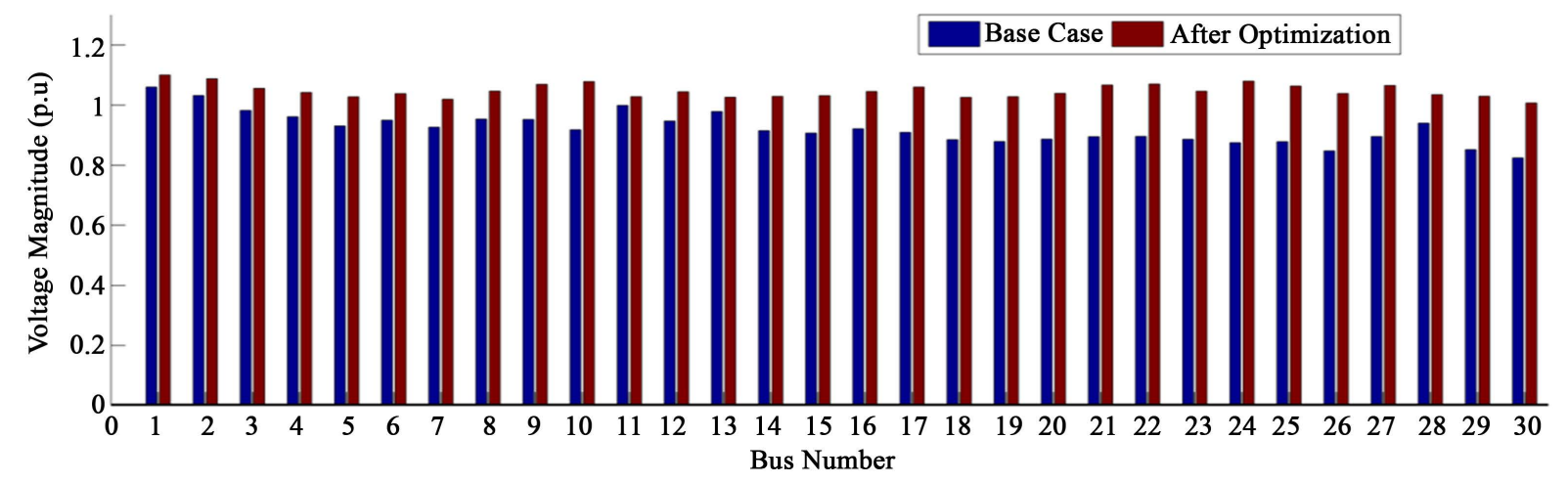

Figure 5. Comparison of voltage levels before and after optimization under heavy loaded condition for IEEE30 bus system. 
is presented. As the $30^{\text {th }}$ bus of the IEEE-30 bus system is found to be the weakest bus, real power at bus number 30 is considered as load parameter in continuation power flow. Under various loading conditions the PV curve is obtained and the comparison of the PV curve before and after optimization is done.

Under Light loaded condition the curve is as shown in Figure 6 and the load ability margin has increased from a value of 0.508603 (p.u) to 0.569762 (p.u).

Under normal loaded condition the curves are Superimposed for cases before and after optimization and are as shown in Figure 7. The loadability margin has increased from a value of 0.481380 (p.u) to 0.563519 (p.u).

Under heavy loaded condition the curves are as shown in Figure 8. The load ability margin has increased from a value of 0.449522 (p.u) to 0.536189 (p.u).

A comparasion of loadability margin for three loading conditions before and after optimization using GRADE algorithm is furnished in Table 9.

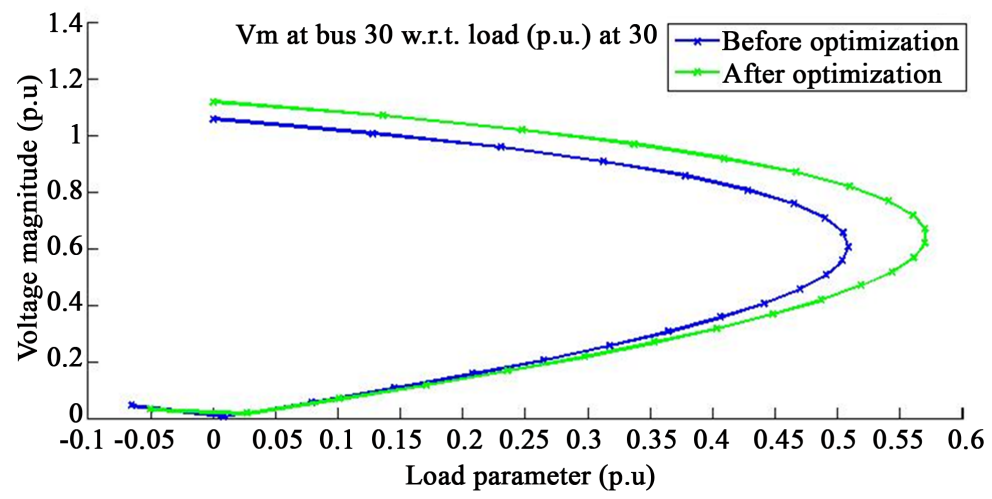

Figure 6. Comparison of PV curve before and after optimization during light loaded condition for IEEE30 bus system.

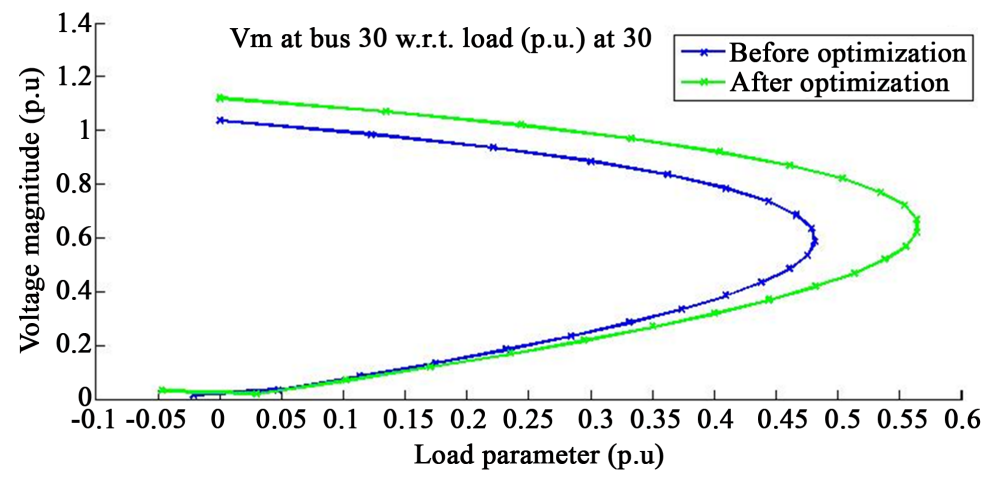

Figure 7. Comparison of PV curve before and after optimization during normal loaded condition for IEEE30 bus system.

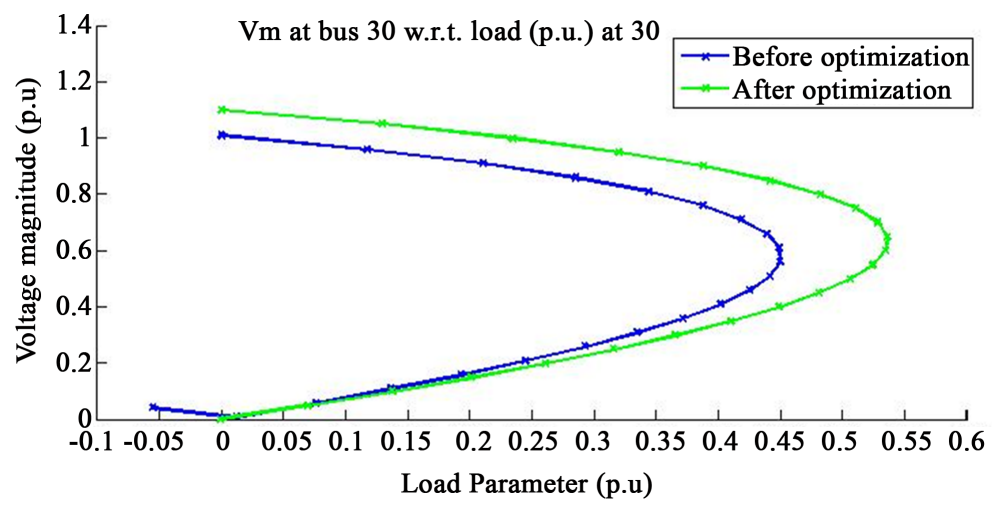

Figure 8. Comparison of PV curve before and after optimization during heavily loaded condition for IEEE30 bus system. 
Table 9. Comparison of loadability margin under three loading conditions for IEEE30 bus system.

\begin{tabular}{cccc}
\hline & & \multicolumn{2}{c}{ Loadability margin(p.u) } \\
\cline { 3 - 3 } Sl. No. & Loading conditions & Before optimisation & After optimisation \\
\cline { 3 - 4 } & Light loaded & 0.508603 & 0.569762 \\
2 & Normal loaded & 0.481380 & 0.563519 \\
3 & Heavy loaded & 0.449522 & 0.536189 \\
\hline
\end{tabular}

From Table 9, it can be observed that Loadability Margin has increased considerably when controllers are set as per the values obtained using GRADE algorithm.

\subsection{IEEE-57 Bus System}

The effectiveness of GRADE algorithm is minimizing the real power losses, improving the voltage profile and enhancing the loadability limit is tested using second test system, viz, IEEE-57 Bus system. The IEEE 57-bus systems [26] consists of 7 generators, 4 transformers, and 80 branches. The reactive power support is provided at the buses 18, 25 and 53 using capacitor bank. The line diagram of IEEE-57 bus test system is shown in Figure 9. The line data and bus data are available in [26].

The reactive power generation limits for the IEEE 57-bus system are listed in Table 10 and The voltage and tap settings limit is shown in Table 11.

Different loading conditions are considered for multi objective optimization. The normal loaded condition has a load of 12.5080 p.u and two other loading conditions of which one is light loaded and the other heavy loaded when compared to that of the normal loaded condition is considered. In light loaded condition the total load is reduced by $50 \%$ of the normal load and in heavy loaded condition the total load is increased by $50 \%$ of the base case as in test system1. The GRADE algorithm was tested for the multi objective optimization problem using MATLAB 7 programming and is run for 30 trials each for different loading conditions in INTEL i5 processor.

Under light loaded condition the load is 6.2540 p.u and the base case loss is obtained as 0.243750 p.u. Under normal loaded condition the load is 12.5080 p.u and the base case loss is obtained as 0.278638 p.u. Under heavy loaded condition the load is 18.7620 p.u and the base case loss is obtained as 1.581204 p.u.

To establish the effectiveness of GRADE algorithm, multi objective optimization for the test system is performed using firefly and particle swarm optimization techniques. Fitness value and real power loss obtained using the above three techniques are compared and tabulated in Table 12 and Table 13 respectively.

From Table 12 and Table 13, it can be observed that GRADE technique is yielding better results compared to result obtained using firefly and particle swarm optimization techniques. The optimal values of the control variables such as generator voltage magnitudes, reactive power rating of capacitor banks and transformer tap settings for the three loading conditions obtained using GRADE algorithm technique is presented in Table 14.

Control Variable are set as per the values obtained by solving multi objective optimization problem using GRADE algorithm and from Table 14, it can be observed that all controllers are set within the given specified limits. The $31^{\text {st }}$ bus of IEEE-57 bus system is found to be the weakest bus. Hence voltage at $31^{\text {st }}$ bus is observed before and after optimization under the three loading conditions to check the effectiveness of GRADE Algorithm. The results are presented in Figures 10-12 respectively.

From Figures 10-12 it is understood that voltage profile at bus no 31 improved considerably when controllers are turned as per the values obtained using GRADE Algorithm.

The result of continuation power flow analysis before and after optimization for different loading conditions is presented. Real power at bus number $31^{\text {st }}$ is considered as the bifurcation parameter for continuation power flow. PV curve is plotted for the three loading conditions, as in the previous test case.

Under Light loaded condition, the super imposed PV curves before and after optimization are shown in Figure 13. The loadability margin has increased from a value of 0.284611 (p.u) to 0.295366 p.u.

Under normal loaded condition the PV curves are obtained before and after optimization and it is presented in Figure 14. It can be seen from Figure 14 that the load ability margin has increased from a value of 0.232494 (p.u) to 0.324625 (p.u). 
Table 10. Limits for reactive power generation for IEEE 57 Bus system.

\begin{tabular}{cccccccc}
\hline Bus No & 1 & 2 & 3 & 6 & 8 & 9 & 12 \\
\hline$Q_{g \min }(M V A R)$ & 0 & -40 & -40 & -40 & -10 & -6 & -6 \\
$Q_{g \max }(M V A R)$ & 10 & 50 & 50 & 40 & 40 & 24 & 24 \\
\hline
\end{tabular}

Table 11. Limits for voltage and tap setting (in p.u.) for IEEE 57 Bus system.

\begin{tabular}{cccccc}
\hline$V_{G}^{\max }$ & $V_{G}^{\min }$ & $V_{\text {load }}^{\max }$ & $V_{\text {load }}^{\min }$ & $T_{k}^{\max }$ & $T_{k}^{\min }$ \\
\hline 1.1 & 0.9 & 1.05 & 0.95 & 1.05 & 0.95 \\
\hline
\end{tabular}

Table 12. Comparison of fitness value for IEEE-57 bus system.

\begin{tabular}{cccccccccccc}
\hline Parameter & \multicolumn{4}{c}{ Lightly loaded condition } & \multicolumn{3}{c}{ Normal loaded condition } & \multicolumn{4}{c}{ Heavily loaded condition } \\
\hline Optimization Technique & Firefly & PSO & GRADE & Firefly & PSO & GRADE & Firefly & PSO & GRADE \\
\hline Fitness Value & 0.42732 & 0.2801 & 0.2797 & 1.093 & 0.3362 & 0.3359 & 4.4924 & 2.0835 & 2.0819 \\
\hline
\end{tabular}

Table 13. Comparison of real power loss for IEEE-57 bus system.

\begin{tabular}{ccccccccccc}
\hline Loading Condition & \multicolumn{3}{c}{ Lightly loaded condition } & \multicolumn{2}{c}{ Normal loaded condition } & \multicolumn{3}{c}{ Heavily loaded condition } \\
\hline Optimization Technique & Firefly & PSO & GRADE & Firefly & PSO & GRADE & Firefly & PSO & GRADE \\
\hline $\mathrm{P}_{\text {loss }}$ (p.u) & 0.19762 & 0.189052 & 0.185047 & 0.27863 & 0.249934 & 0.243697 & 1.30134 & 1.2899 & 1.284536 \\
\hline
\end{tabular}

Table 14. Optimal values of the control variables in p.u. obtained using GRADE algorithm for IEEE-57 bus system.

\begin{tabular}{|c|c|c|c|c|c|c|c|}
\hline $\begin{array}{c}\text { Control } \\
\text { variables }\end{array}$ & $\begin{array}{l}\text { Lightly loaded } \\
\text { condition }\end{array}$ & $\begin{array}{c}\text { Normal loaded } \\
\text { condition }\end{array}$ & $\begin{array}{l}\text { Heavily loaded } \\
\text { condition }\end{array}$ & $\begin{array}{c}\text { Control } \\
\text { variables }\end{array}$ & $\begin{array}{l}\text { Lightly loaded } \\
\text { condition }\end{array}$ & $\begin{array}{c}\text { Normal loaded } \\
\text { condition }\end{array}$ & $\begin{array}{c}\text { Heavily loaded } \\
\text { condition }\end{array}$ \\
\hline $\mathrm{V}_{1}$ & 1.08623 & 1.1 & 1.1 & $\mathrm{~T} 7$ & 1.04543 & 0.95 & 0.989527 \\
\hline $\mathrm{V}_{2}$ & 1.09163 & 1.1 & 1.1 & $\mathrm{~T} 8$ & 0.988768 & 0.95 & 0.95 \\
\hline $\mathrm{V}_{3}$ & 1.09716 & 1.1 & 1.1 & T9 & 0.95 & 1.05 & 0.950728 \\
\hline $\mathrm{V}_{6}$ & 1.1 & 1.1 & 1.1 & $\mathrm{~T} 10$ & 1.02535 & 0.95 & 0.95 \\
\hline $\mathrm{V}_{8}$ & 1.1 & 1.1 & 1.1 & $\mathrm{~T} 11$ & 0.968509 & 0.96518 & 0.95 \\
\hline $\mathrm{V}_{9}$ & 1.07875 & 1.1 & 1.1 & $\mathrm{~T} 12$ & 0.981064 & 0.95 & 1.01125 \\
\hline $\mathrm{V}_{12}$ & 1.07661 & 1.1 & 1.1 & $\mathrm{~T} 13$ & 0.964782 & 1.05 & 0.995869 \\
\hline $\mathrm{Q}_{\mathrm{C} 18}$ & -2.86067 & 20 & 20 & $\mathrm{~T} 14$ & 1.00633 & 0.95 & 0.990177 \\
\hline $\mathrm{Q}_{\mathrm{C} 25}$ & -0.455466 & 20 & 20 & $\mathrm{~T} 15$ & 0.989047 & 0.95 & 1.05 \\
\hline $\mathrm{QC}_{53}$ & 0.204621 & 13.1967 & 20 & $\mathrm{Qg}_{1}$ & 2.79599 & 0 & 3.61023 \\
\hline $\mathrm{T}_{1}$ & 1.04844 & 0.95 & 0.95 & $\mathrm{Qg}_{2}$ & -17.3942 & -40 & 50 \\
\hline $\mathrm{T}_{2}$ & 1.04991 & 0.95016 & 0.95 & $\mathrm{Qg}_{3}$ & 50 & -40 & 15.4129 \\
\hline $\mathrm{T}_{3}$ & 0.96976 & 0.95 & 0.95 & $\mathrm{Qg}_{6}$ & 20.2413 & -18.1918 & -28.3228 \\
\hline $\mathrm{T}_{4}$ & 0.995547 & 1.05 & 0.955142 & $\mathrm{Qg}_{8}$ & 34.9479 & -10 & 20.2949 \\
\hline $\mathrm{T} 5$ & 0.973679 & 0.95 & 1.00837 & $\mathrm{Qg}_{9}$ & 14.3681 & 24 & -6 \\
\hline T6 & 0.95073 & 0.95 & 0.95 & $\mathrm{Qg}_{12}$ & 6.1866 & 24 & -6 \\
\hline
\end{tabular}




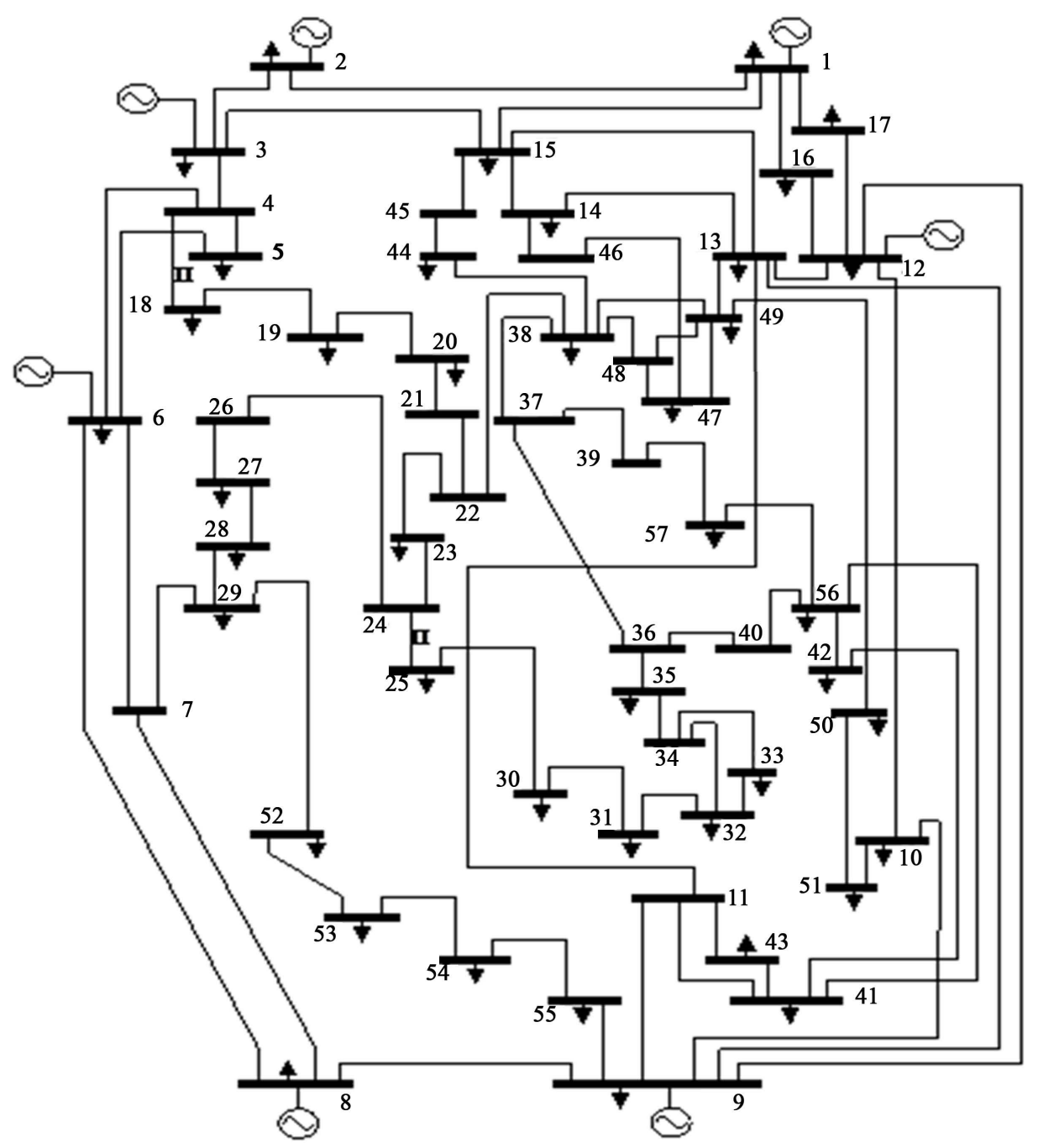

Figure 9. Single line diagram of IEEE 57 bus system.

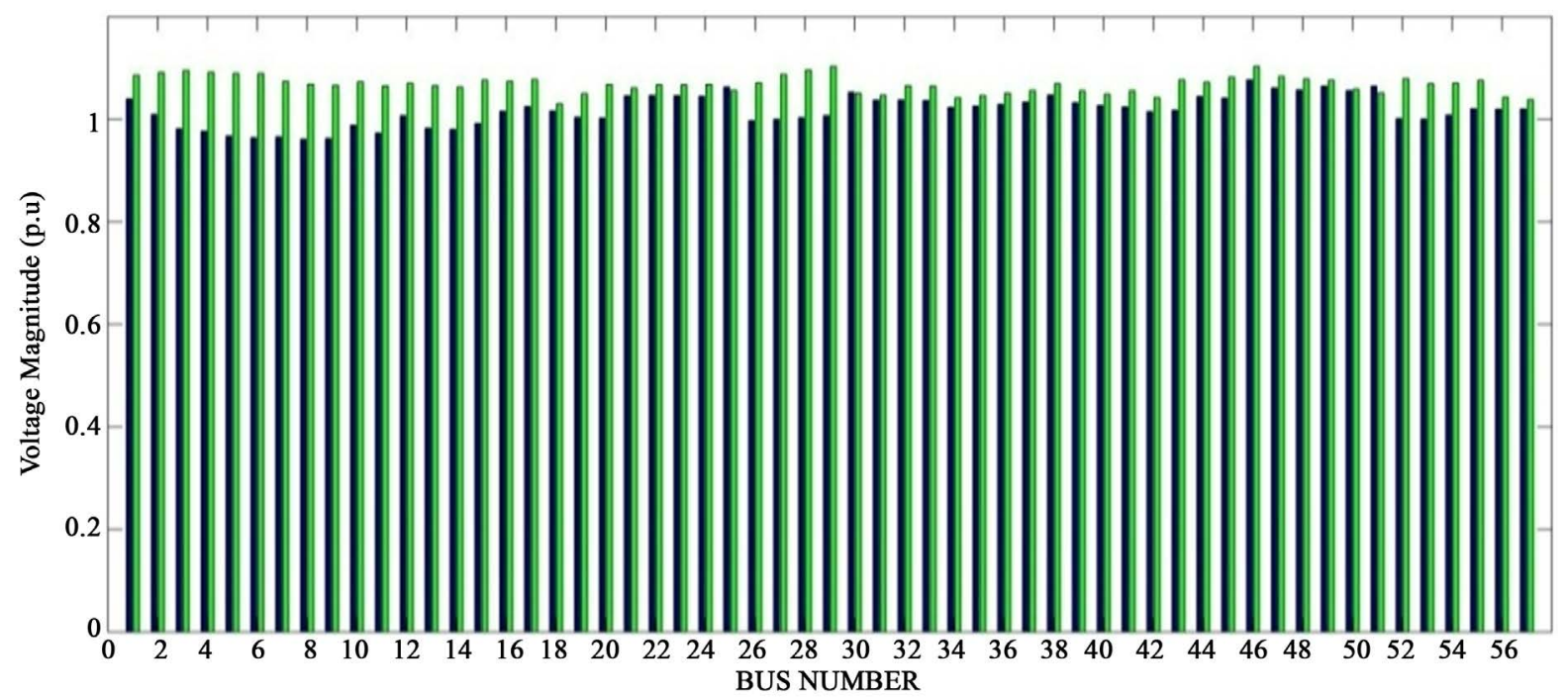

Figure 10. Comparison of voltage levels before and after optimization for light loaded condition for IEEE-57 bus system.

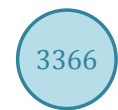




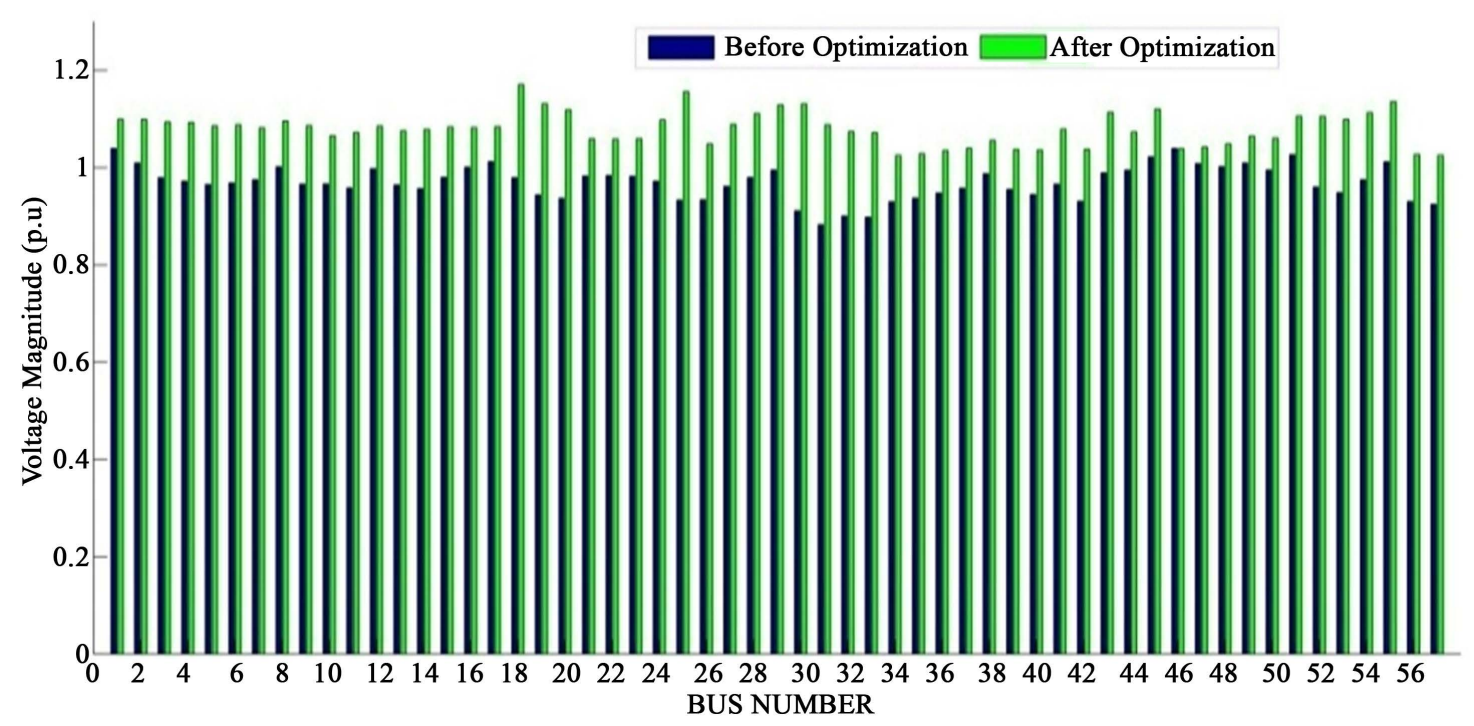

Figure 11. comparison of voltage levels before and after optimization under normal loaded condition for IEEE-57 bus system.

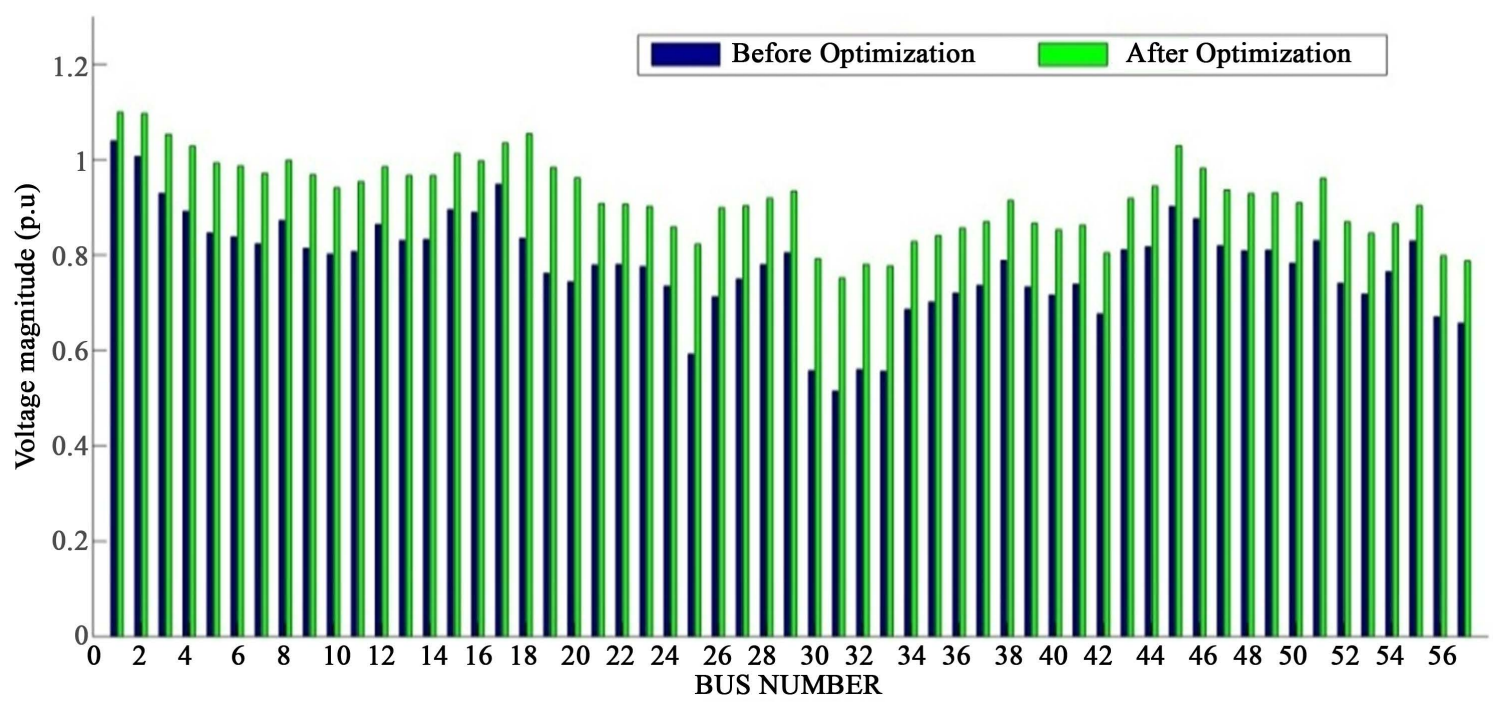

Figure 12. Comparison of voltage levels before and after optimization under heavily loaded condition for IEEE-57 bus system.

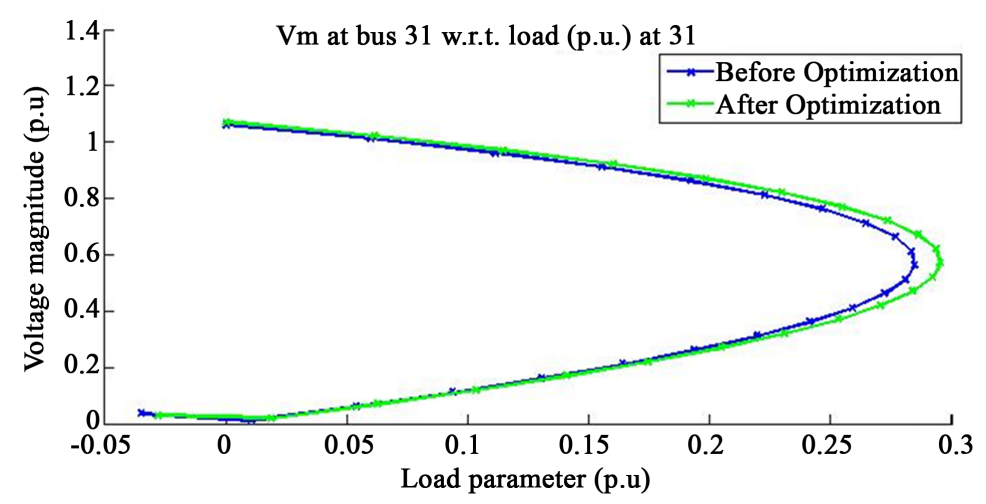

Figure 13. Comparison of PV curve before and after optimization during light loaded condition for IEEE-57 bus system.

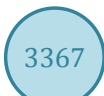


Under heavy loaded condition the total load is increased by 50\% of normal load in all load buses. The PV curves are obtained before and after optimization and presented in Figure 15. The loadability margin has increased from a value of 0.449522 (p.u) to 0.536189 (p.u).

A comparasion of loadability margin under three loading conditions before and after optimization obtained using GRADE algorithm is furnished in Table 15 for the second test system.

From Table 15, it is corroborated, once again that load ability margin gets enhanced when controller variables are set using the optimized solution from GRADE algorithm based approach. A Comparison of convergence time incurred for the two test systems under three loading conditions using three techniques, viz, firefly, Particle swarm optimization and GRADE is furnished in Table 16.

From Table 16, it can be observed that GRADE Algorithm converges quickly compared to firefly and Particle swarm optimization Techniques in all the three loading conditions.

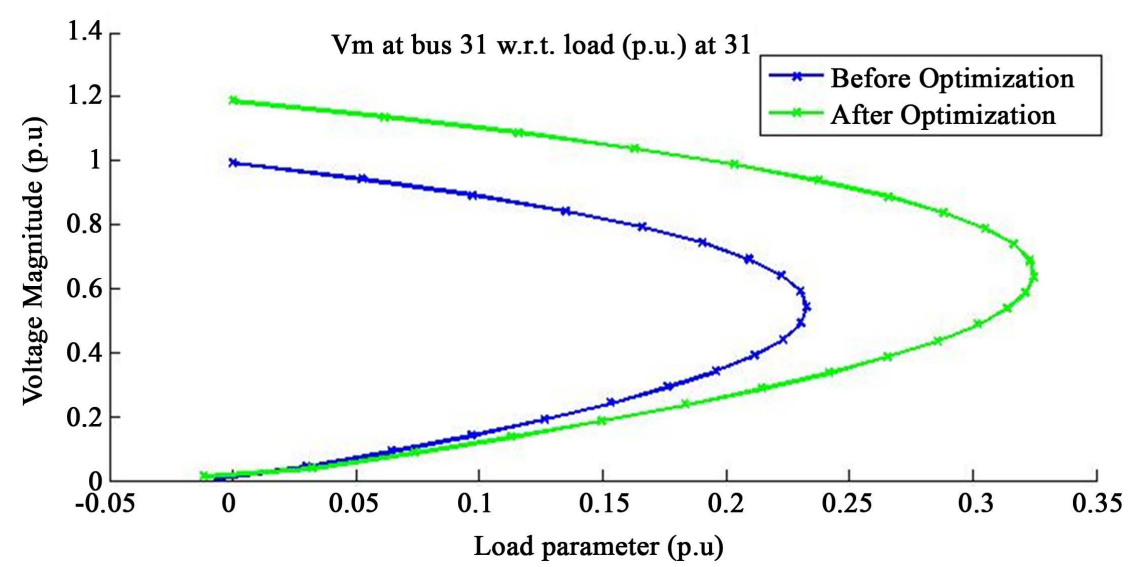

Figure 14. Comparison of PV curve before and after optimization during normal loaded condition for IEEE-57 bus system.

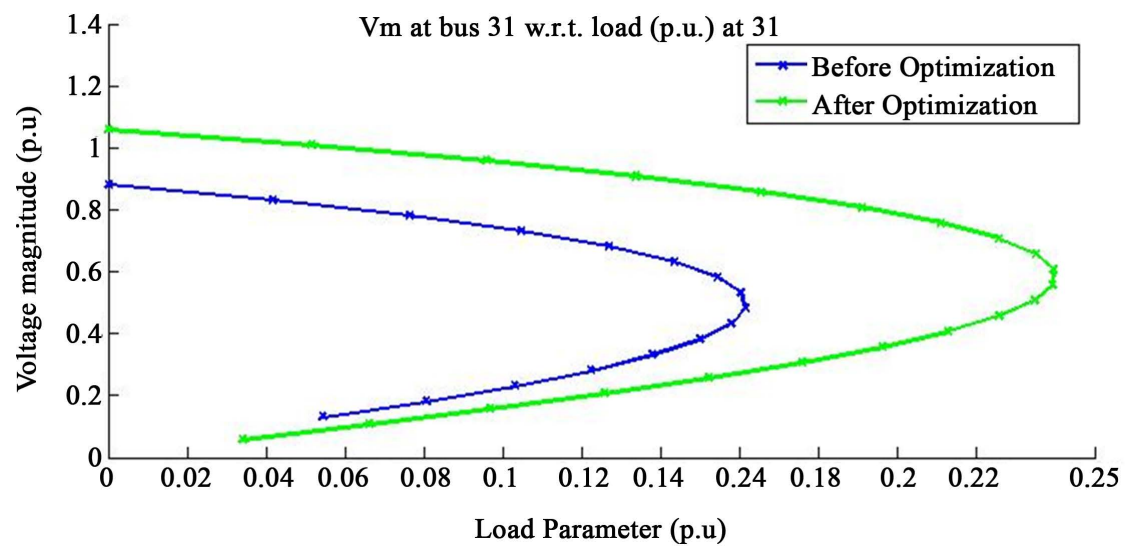

Figure 15. Comparison of PV curve before and after optimization during Heavily loaded condition for IEEE-57 bus system.

Table 15. Comparison of loadability margin under three loading conditions for IEEE-57 bus system.

\begin{tabular}{cccc}
\hline & & \multicolumn{2}{c}{ Loadability margin(p.u) } \\
Sl. No. & Loading conditions & Before optimisation & After optimisation \\
\cline { 3 - 4 } 1 & Light loaded & 0.284611 & 0.295366 \\
2 & Normal loaded & 0.232494 & 0.324625 \\
3 & Heavy loaded & 0.449522 & 0.536189 \\
\hline
\end{tabular}


Table 16. Comparison of Convergence time for the two test systems under three loading condition for 30 trial.

\begin{tabular}{|c|c|c|c|c|c|c|c|c|c|c|c|c|c|c|c|c|c|}
\hline \multicolumn{9}{|c|}{ IEEE 30 Bus system } & \multicolumn{9}{|c|}{ IEEE 57 Bus system } \\
\hline \multicolumn{3}{|c|}{ Firefly } & \multicolumn{3}{|c|}{ PSO } & \multicolumn{3}{|c|}{ GRADE } & \multicolumn{3}{|c|}{ Firefly } & \multicolumn{3}{|c|}{ PSO } & \multicolumn{3}{|c|}{ GRADE } \\
\hline $\mathrm{L}$ & $\mathrm{N}$ & $\mathrm{H}$ & $\mathrm{L}$ & $\mathrm{N}$ & $\mathrm{H}$ & $\mathrm{L}$ & $\mathrm{N}$ & $\mathrm{H}$ & $\mathrm{L}$ & $\mathrm{N}$ & $\mathrm{H}$ & $\mathrm{L}$ & $\mathrm{N}$ & $\mathrm{H}$ & $\mathrm{L}$ & $\mathrm{N}$ & $\mathrm{H}$ \\
\hline 10 & 8 & 15 & 12 & 7 & 13 & 5 & 4 & 8 & 19 & 15 & 25 & 21 & 11 & 23 & 15 & 8 & 16 \\
\hline
\end{tabular}

L—Light loaded condition; N—Normal loaded Condition; H—Heavy loaded condition.

\section{Conclusion}

A GRADE algorithm based approach is presented along with PV analysis to solve multi objective optimization problem of minimizing real power losses and improving the voltage profile and hence enchancing the Performance of power systems. Real and Reactive power losses are considered as equality constraints. Inequality constraints comprised of generator bus voltages, transformer tap settings, reactive power ratings at the capacitor banks and reactive power generation at generator buses. The GRADE Algorithm based optimization approach is developed using $\mathrm{M}$ coding in MATLAB plat form. To illustrate the effectiveness of the GRADE Algorithm based approach, studies are performed in two test systems, viz, IEEE 30 bus system and IEEE 57-bus system for three loading conditions. Results obtained using GRADE Algorithm are compared with the results obtained using firefly algorithm and particle swarm optimization technique. In all the three loading conditions tested, GRADE Algorithm based optimization approach yielded reduced real power loss and improved voltage profile. It is also observed through PV curve using continuation power flow that loadability margin increased considerably when control variable values are tuned using GRADE Algorithm based approach. Hence it is concluded that, the GRADE algorithm performs better than the firefly and particle swarm optimization techniques, in terms of convergence time, reduction in real power losses, improving voltage profile and enchancing the load ability margin of power systems.

\section{References}

[1] Abou El Ela, A.A., Abido, M.A. and Spea, S.R. (2011) Differential Evolution Algorithm for Optimal Reactive Power Dispatch. Electric Power Systems Research, 81, 458-464.

[2] Khazali, A.H. and Kalantar, M. (2011) Optimal Reactive Power Dispatch Based on Harmony Search Algorithm. International Journal of Electrical Power \& Energy Systems, 33, 684-692.

[3] Saraswat, A. and Saini, A. (2013) Multi-Objective Optimal Reactive Power Dispatch Considering Voltage Stability in Power Systems Using HFMOEA. Engineering Applications of Artificial Intelligence, 26, 390-404.

[4] Bhattacharya, A. and Chattopadhyay, P.K. (2010) Solution of Optimal Reactive Power Flow Using Biogeography-Based Optimization. International Journal of Electrical \& Electronics Engineering, 4, 8.

[5] Shunmugalatha, A. and Slochanal, S.M.R. (2008) Application of Hybrid Multiagent-Based Particle Swarm Optimization to Optimal Reactive Power Dispatch. Electric Power Components and Systems, 36, 788-800.

[6] Mandal, B. and Roy, P.K. (2013) Optimal Reactive Power Dispatch Using Quasi-Oppositional Teaching Learning Based Optimization. International Journal of Electrical Power \& Energy Systems, 53, 123-134.

[7] Bhattacharya, B. and Goswami, S.K. (2007) Reactive Power Optimization through Evolutionary Techniques. A Comparative Study of the GA, DE and PSO Algorithms. Intelligent Automation and Soft Computing, 13, 453-461.

[8] Bhagwan Das, D. and Patvardhan, C. (2002) Reactive Power Dispatch with a Hybrid Stochastic Search Technique. International Journal of Electrical Power \& Energy Systems, 24, 731-736.

[9] Devaraj, D. and Roselyn. J.P. (2010) Genetic Algorithm Based Reactive Power Dispatch for Voltage Stability Improvement. International Journal of Electrical Power \& Energy Systems, 32, 1151-1156.

[10] Saadat, H. (2004) Power System Analysis. McGraw-Hill Publications.

[11] Ramirez, J.M., Gonzalez, J.M. and Ruben, T.O. (2011) An Investigation about the Impact of the Optimal Reactive Power Dispatch Solved by DE. International Journal of Electrical Power \& Energy Systems, 33, 236-244.

[12] Devaraj, D. (2007) Improved Genetic Algorithm for Multi Objective Reactive Power Dispatch Problem. European Transaction on Electrical Power, 17, 569-581.

[13] Lenin, K. and Mohan, M.R. (2006) Ant Colony Search Algorithm for Optimal reactive Power Optimization. Serbian Journal of Electrical Engineering, 3, 77-88. 
[14] Das, D.B. and Patvardhan, C. (2003) A New Hybrid Evolutionary Strategy for Reactive Power Dispatch. Electrical Power System Research, 65, 83-90.

[15] Varadarajan, M. and Swarup, K.S. (2008) Differential Evolution Approach for Optimal Reactive Power Dispatch. Applied Soft Computing, 8, 1549-1561.

[16] Mahadevan, K. and Kannan, P.S. (2010) Comprehensive Learning Particle Swarm Optimization for Reactive Power Dispatch. Applied Soft Computing, 10, 641-652. http://dx.doi.org/10.1016/j.asoc.2009.08.038

[17] Azimi, R. and Esmaeili, S. (2013) Multi-Objective Daily Volt/VAr Control in Distribution Systems with Distributed Generation Using Binary Ant Colony Optimization. Turkish Journal of Electrical Engineering and Computer Sciences, 21, 613-629.

[18] Jeyadevi, S., Baskar, S., Babulal, C.K. and Iruthayarajan, M.W. (2011) Solving Mutiobjective Optimal Reactive Power Dispatch Using Modified NSGA-II. International Journal of Electrical Power \& Energy Systems, 33, 219-228. http://dx.doi.org/10.1016/j.ijepes.2010.08.017

[19] Ramesh, S., Kannan, S. and Baskar, S. (2012) An Improved Generalized Differential Evolution Algorithm for MultiObjective Reactive Power Dispatch. Engineering Optimization, 44, 391-405. http://dx.doi.org/10.1080/0305215X.2011.576761

[20] Lin, X., David, A.K. and Yu, C.W. (2003) Reactive Power Optimization with Voltage Stability Consideration in Power Market Systems. IEE Proceedings—Generation, Transmission and Distribution, 150, 305-310. http://dx.doi.org/10.1049/ip-gtd:20030198

[21] Yang, X.-S. (2010) Nature Inspired Meta-Heuristic Algorithms. Luniver Press, China.

[22] Zhang, X.R., Chen, W.R., Dai, C.H. and Cai, W.Z. (2010) Dynamic Multi-Group Self-Adaptive Differential Evolution Algorithm for Reactive Power Optimization. International Journal of Electrical Power \& Energy Systems, 32, 351357. http://dx.doi.org/10.1016/j.ijepes.2009.11.009

[23] Pal, S.K., Rai, C.S. and Singh, A.P. (2012) Comparative Study of Firefly Algorithm and Particle Swarm Optimization for Noisy Non-Linear Optimization Problems. International Journal of Intelligent Systems and Applications, 10, 50-57. http://dx.doi.org/10.5815/ijisa.2012.10.06

[24] Li, H.X., Li, Y.H. and Chen, J.F. (2014) Adaptive Multiple Evolutionary Algorithms Search for Multi-Objective Optimal Reactive Power Dispatch. International Transactions on Electrical Energy Systems, 24, 780-795. http://dx.doi.org/10.1002/etep.1730

[25] Mousavi, O.A., Bozorg, M. and Cherkaoui, R. (2013) Preventive Reactive Power Management for Improving Voltage Stability Margin. Electric Power Systems Research, 96, 36-46. http://dx.doi.org/10.1016/j.epsr.2012.10.005

[26] Power System Test Case Archive. http://www.ee.washington.edu/research/pstca/

\section{Submit or recommend next manuscript to SCIRP and we will provide best service for you:}

Accepting pre-submission inquiries through Email, Facebook, LinkedIn, Twitter, etc.

A wide selection of journals (inclusive of 9 subjects, more than 200 journals)

Providing 24-hour high-quality service

User-friendly online submission system

Fair and swift peer-review system

Efficient typesetting and proofreading procedure

Display of the result of downloads and visits, as well as the number of cited articles

Maximum dissemination of your research work

Submit your manuscript at: http://papersubmission.scirp.org/ 